\section{Engineered Coasts}

\section{Edited by Jiyu Chen, Doeke Eisma, Kenji Hotta, and H. Jesse Walker}

Kluwer Academic Publishers, Dordrecht, 2002. 312 pp. EUR 99, USD 97, GBP 66. ISBN 1-4020-0521-0.

This volume, the sixth in a series dealing with "Coastal Systems and Continental Margins", focuses on shorelines which have undergone a substantial degree of human modification. The authors of the various chapters work in China, The Netherlands, USA, Japan, and UK, and these coastlines form the focus of most of the discussion, although examples from other regions are discussed as well. The main subject areas considered include beach nourishment, management of natural deltaic distributaries and tidal channels, infilling of embayments, reclamation in deltaic regimes, coastal protection and seawall construction, and port development. The volume is intended as a general reference for geoscientists, and discusses the issues as geological case studies in a general fashion, without presenting technical engineering details or socio-economic analysis. It thus serves as a useful introduction for the geoscientist interested in coastlines that have undergone engineering modification.

The first chapter, by C.W. Finkl and H.J. Walker, discusses beach nourishment, an engineering response to the natural phenomenon of erosion in response to diminished sediment supply. The interrelations between beaches and dunes are stressed. Different practices in different political jurisdictions, both with respect to building construction and nourishment policy, are reviewed, and an overview of nourishment techniques is presented. "Soft" engineering approaches are discussed, but it is emphasized that these provide only temporary relief to a beach system subject to erosion.

Walker and Finkl follow the general discussion with the presentation of a series of case studies in Chapter 2. The focus is on comparative analysis of the methods used in northwestern Europe, Portugal, Georgia (Black Sea), USA, Japan, Australia, and New Zealand. In particular, interesting discussions are provided for New Zealand and Tokyo Bay.

Channels in the Mississippi River Delta are the focus of Chapter 3, by H.J. Walker and D.W. Davis. The history of delta development, both natural and human-influenced, is reviewed, including a discussion of the efforts required to maintain the shipping channels. The role of the Mississippi's

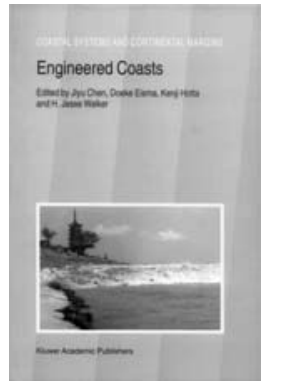

Tokyo Bay is the subject of Chapter 4, by $\mathrm{K}$. Hotta, who recounts the history of infilling of the bay, dating from 1868. The overall infilling efforts are described, including a discussion of the methods of bulkhead construction and installation, and the issues involved in the construction of the "Aqualine" highway bridge-tunnel route across the bay.

In Chapter 5, K. Hotta looks at offshore construction and space utilization in Japan. This chapter includes a theoretical discussion of space utilization, analysis of styles of offshore construction, and discusses planning flexibility. Examples of offshore island construction, fishing port design and maintenance, and floating platforms (not subject to earthquake damage) are presented. Environmentally-sensitive engineering, important in the coastal zone, is also treated well.

H. Zengchui and D. Zeheng analyze reclamation efforts in the Qiantang Estuary. Discussion of historical changes in the coastline includes consideration of the initial preservation measures undertaken during the Qing Dynasty. The tidal estuary is marked by frequent channel shifts, challenging coastal engineers to keep access to Hangzhou open to shipping. Modern engineering practice involves working with tidal currents and the river to design channels and port facilities that are less susceptible to siltation. In the following chapter, J. Wei and T. Cunhuan analyze the seawall in Qiantung Estuary, including discussion of hydrodynamic conditions, and seawall design in light of the underlying sediments.

H.J. Walker considers marinas, sealevel reservoirs, solar salt pans, and other artificial shorelines in Chapter 8. This chapter provides numerous examples of the various artificial features constructed along engineered coastlines, and is well illustrated. Among other examples, aquaculture operations undertaken by the aboriginal Hawaiians, and tsunami protection structures are discussed.

C. Jiyu and L. Daoji investigate the regulation of Changjiang Estuary. They present general data concerning the estuary, documenting repeated episodes of channel shifting, the history of regulation, and numerous storm events. As the port of Shanghai depends upon access through this estuarine tionary trends of the modern Pearl River Delta; the construction of dykes to allow cultivation, including the ridge-pond agricultural system; the central sluice projects; the planning of regulation efforts in the estuary; and the implications for oyster aquaculture.

J. van de Graaff considers coastal protection in The Netherlands. Issues include the structural erosion of coasts, beach and dune erosion during storm surges, protection of newly reclaimed areas, and stabilization of dynamic tidal inlets. Discussion focuses on the use of engineering structures, and the reaction of the coastline to the imposition of engineering works.

The Delta Project in The Netherlands is discussed in Chapter 12 by G. Schiereck. Storm surges, water management, access to the port of Rotterdam, and the shellfish industry are some of the issues that Delta Project designers were required to address before the coastline could be successfully engineered. The technical and environmental aspects are considered in this interesting chapter. In Chapter 13, Rotterdam Harbour is the focus of a specific analysis by $G$. Schiereck and D. Eisma. Canal construction, breakwater design, dredging, traffic control, pollution, and hydrological issues are discussed. M. Stive and R. Waterman present an analysis of the Zuyder Zee Project, beginning with the first proposals in 1667 and continuing to the present.

C. Vos analyses the Thames Barrier in the final chapter of the volume. The history of flooding on the Thames is discussed, and the issues surrounding the positioning of the barrier considered. The design and construction techniques, the process of construction, and the history of barrier operations are considered in sequence.

Engineered Coasts provides a useful overview of the geological factors involved in coastal engineering efforts. At the same time, it allows geoscientists to assess the role that our profession should play in helping with engineering design in coastal environments.

\section{Norm Catto}

Department of Geography

Memorial University

St John's, NL, A1B $3 X 9$

CANADA

ncatto@mun.ca 


\section{Geodynamics}

\section{Second edition}

\section{by Donald L. Turcotte and Jerry Schubert}

Cambridge University Press, 2002. 456 pages. ISBN 0521666244 (paperback), $£ 29.95$ (US\$45.00); ISBN 052166186 2 (hardback), £75.00 (US\$110.00)

The classic textbook by Turcotte and Schubert should be found in the library of every earth scientist. The quantification of solid earth processes is currently a challenge and will remain so well into the future for many research efforts. Regardless of one's disciplinary background (sedimentologist, structural geologist, geochemist, petroleum geologist, geophysicist, etc.) some day or possibly every day a question will arise that is addressed in the text by Turcotte and Schubert. The book is truly a reference text.

The topics in the text range from solidstate mechanics and rheology to fluid mechanics and solid/fluid motion with the Earth while taking into account heat transfer. Tectonics, gravity as well as isotopic geochemistry are included. The presentation of information is often condensed by clear and adequately accompanied by exercises with helpful solution hints. Chapter 1 deals with Plate Tectonics, Chapter 2 Stress and Strain in Solids, Chapter 3 Elasticity and Flexure, Chapter 4 Heat Transfer, Chapter 5 Gravity, Chapter 6 Fluid Mechanics, Chapter 7 Rock Rheology, Chapter 8 Faulting, Chapter 9 Flows in Porous Media and Chapter 10 Chemical Geodynamics.

This second edition book contains additional information and chapters not found in the first edition and several of the other chapters have been slightly restructured. Tables of values have been partly updated, especially in the domain of space. The details about planets has been updated and GPS has now been introduced. Some of the topics were significantly improved because of new developments in the field since publication of the first edition. For instance, Hotspots are described and an interesting model is presented; a plate cooling model for the lithosphere has been added; the Culling model for erosion/deposition is appropriately presented in the heat transfer chapter; topography and magnitude of horizontal forces are estimated; thermal convection is presented on both transient and steady-state boundary layer theories; a mantle recycling and mixing theory is presented while taking into account both geochemistry and deformation; the strength envelope of oceanic lithosnhere is presented and an entire

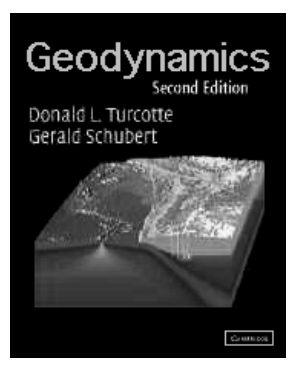

Most of the relevant solid earth physics topics are presented in the second edition, but the addenda appear less inspired than the subjects developed in the first edition. The new ideas and applications in geodynamics are only partially introduced in this new edition. It would have been more interesting to include several new paragraphs dedicated to the new interpretations and applications of solid earth physics. It is regrettable that certain figures were not updated and replaced by more recent illustrations, this is particularly true for the section on continental drift. As a consequence, the recent references and the number of references is actually quite limited.

Unfortunately several topics are only partially mentioned including: physics linked to sedimentary basins, modeling deformation and heating of mountain chains, quantification of erosion processes, post-glacial rebound and earthquakes and so on. All of these topics are now becoming more popular and have been well investigated during the past 20 years. Both authors are excused from these omissions since the two have been on the forefront of advancing many of the topics themselves.

Researchers interested in one or more of the topics in this book will find the need to consult the text if not fully read the entire volume. The variety of topics presented quite extensively and with such detailed mathematics is amazing. Although the second edition is slightly disappointing some 20 years after the first edition, the new text is truly irreplaceable. Thank you, Donald Turcotte and Gerald Schubert!

\section{Michel Jaboyedoff \\ Quanterra \\ SWITZERLAND}

\section{Islands of the Arctic}

\section{by Julian Dowdeswell and Michael Hambrey}

\author{
Cambridge University Press, 2002. \\ Hardback, xvi+280pages, ISBN 0521 \\ 813336
}

Julian Dowdeswell and Michael Hambrey are prominent specialists in the physical geography and glaciology of the Polar Regions. Now their experience and their profound background knowledge have been condensed into Islands of the Arctic, an album with over 200 stunning photographs and diagrams, useful not only for the Arctic enthusiast and seasoned traveler but also the Arctic geosciences explorer, whether he is a beginner or well experienced in the field.

Different from many books and articles written and issued, as well as television programs made about the Arctic, this book, or album, pays more attention to the physical environment -- the physical and biological landscape and the evolution of the Arctic islands. The book provides lots of information about the landscape of the Arctic islands, and how it influences, and is influenced by, animals (including humans) and plants.

The book contains an introduction to the geography of the Arctic islands, and eight chapters: Chapter 2 Evolution of the Arctic Islands; Chapter 3 Weather, Climate and Atmospheric effects; Chapter 4 Glaciers and Ice Sheets; Chapter 5 Icebergs and Sea Ice; Chapter 6 Frost Action; Chapter 7 Arctic Coasts, Rivers and Lakes; Chapter 8 Animals and Plants; Chapter 9 Indigenous Peoples, Exploration and Environmental Impacts. The Postscript is titled The Future of the Arctic Islands.

The authors, firstly, describe briefly the principal topographic and physical features of each major archipelago of the Arctic, to set the scene. The photographs, selected primarily by the authors from their own collections during more than two decades of field seasons in the Arctic, and maps are really helpful for readers to acquire visual vivid images from the Canadian Arctic archipelago, eastwards through Greenland and Svalbard to the Russian Arctic islands. The comprehensive introduction is impressive, showing the value of the authors' long-term work in this vast, harsh and little-visited region.

Rocks outcropping on the islands are fundamental for understanding the Arctic islands today. The oldest sedimentary rock on the earth occurs in Greenland. The geological history of the region can be traced back 3,800 million years. The book outlines the major geological processes and tectonic units of the Arctic. Some Arctic islands were once parts 


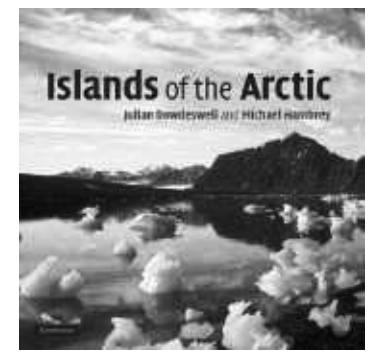

years, finally resulting in the formation of the Arctic as we know it today. The authors' exquisite photographs and maps are informative, and stir the readers' imagination to experience the glacial world of about 650 million years ago, when most of the earth was probably covered with ice and snow, similar to the Ice Age 18,000 years ago.

The authors are familiar with the nature of Arctic weather and climate, and climate changes in the last 100,000 years or so. They discuss glaciers, ice sheets, icebergs and sea ice systematically, and explain how they change in response to climate changes. The book deals with the all-pervasive presence of frozen ground and vigorous frost activity, which are unique to the Arctic on land. Coasts, rivers and lakes are presented as highly dynamic environments, and as other aspects of the landscape of the Arctic islands. The relationship between Arctic wildlife and the environment, and the impact of human activity are also given attention.

As outstanding glaciologists, the authors explain how the Arctic sea ice is shrinking in area and thinning, whilst most glaciers are thinning and receding, contributing to a rise in the overall sea level. As observed in the Antarctic, too, a hole has developed in the ozone layer over the Arctic, and the climate certainly seems to be getting warmer. The Arctic faces a more insidious threat, unconnected with any activity in the region itself: global warming.
At the end of the book, the Arctic explorers investigate the rapid recession of tidewater glaciers in northwest Spitsbergen in the late summer, which is sometimes linked to global warming. They feel strongly about the global effects of climate change in the Arctic, with profound effects on the ecological balance. That is the glaciologists' real story.

Yue ZHAO

Research Professor and Director

Division of Polar Geology

Chinese Academy of Geological Sciences

11\# Min Da Nan Lu

100081 Beijing,

CHINA

E-mail:yuezhao@public3.bta.net.cn

\section{Hutchison "Young Scientist" Foundation}

William Watt Hutchison, "Hutch" to his many friends around the world, was a Scots-born Canadian geologist who served Canada and the IUGS in myriad dynamic and creative ways. Most notably, he served as the IUGS Secretary General (1976-1980) at a pivotal time in its history, and as IUGS President (1984-1987). The same boundless energy, enthusiasm, skill in communications, and ability to foster teamwork that characterized his work with the IUGS also carried him to preeminent scientific administrative positions in the Canadian Government, where he served as Director General of the Geological Survey of Canada and as Assistant Deputy Minister of Earth Sciences. His distinguished career was terminated in 1987 by his untimely death at the age of 52, following a painful struggle with cancer.

One of Hutch's last wishes was to establish under IUGS auspices a memorial foundation intended to promote the professional growth of deserving, meritorious young scientists from around the world by supporting their participation in important IUGS-sponsored conferences. The first 3 beneficiaries of the Hutchison "Young Scientist" Foundation attended the 28th International Geological Congress (IGC) in Washington, D.C., in 1989.

Initially, earned interest on the funds available to the Hutchison Foundaton were insufficient to sustain comparable grants every four years without seriously eroding the principal. For that reason, the IUGS made no grants from the Foundation for the 30th IGC (1996), preferring instead to strengthen the fund by allowing it to earn interest for a longer period of time and by appealing for donations from the international geologic community. Grants from the Foundation again supported deserving young scientists beginning with the 31st IGC (2000), and should continue for future Congresses. The IUGS would like to expand the resources of the Foundation to make it possible also to offer support to deserving young scientists to attend other important IUGS-sponsored scientific meetings.

The Hutchison "Young Scientist" Foundation is a worthy cause that honors a fine, caring man and a distinguished, public-spirited scientist and administrator. The foundation also celebrates and promotes those things that gave Hutch the most professional satisfaction: geology, international scientific collaboration, and stimulating young minds.

The IUGS welcomes contributions to the Hutchison "Young Scientist" Foundation. Please send donations to:

\section{Dr. Antonio Brambati \\ IUGS Treasurer}

Dept. of Geological, Environmental and Marine Sci. (DiSGAM),

University of Trieste, 1-34127 Trieste

ITALY

Tel: +39040 558 2046; Fax: +39040 5582048

E-mail: brambati@univ.trieste.it

Checks in US dollars or Visa/Mastercard (please include account number and expiration date) are preferred in order to avoid the high cost of currencv conversions. Residents of the IJ.S.A. are reminded that charitahle oifts of this nature are tax deductihle. 